TRAMES, 2013, 17(67/62), 2, 175-195

\title{
"DRAGON, KUNG FU AND JACKIE CHAN...": STEREOTYPES ABOUT CHINA HELD BY MALAYSIAN STUDENTS
}

\author{
Larisa Nikitina and Fumitaka Furuoka
}

University of Malaya

\begin{abstract}
This study explored stereotypes about China held by young Malaysians. It focused on the learners of the Mandarin language in a big public university. The study not only examined the content but also assessed the favourability and salience of the language learners' stereotypes, which had not been done in the previous studies. The stereotypes about China provided by the participants were diverse; they referred to culture, politics, language, history, climate, landscape, economics, religion and the Chinese people. Overall, the stereotypes were favourable. Especially the stereotypes referring to Chinese traditional and popular culture and cultural symbols were among the most frequent and most salient images of China. An interesting finding was that transnational popular culture played an important role in the formation of the stereotypical images about China. The study concludes by highlighting some pedagogical implications based on these findings.
\end{abstract}

Keywords: country stereotypes, salience index, university students, Mandarin language, China, Malaysia

DOI: $10.3176 /$ tr.2013.2.05

\section{Introduction}

China's ascendance in global politics and economy has heightened the interest of the mass media and the general public toward the country. Perceptions about China have fluctuated over the years and between the countries. In 2005, a BBC World Service survey of public opinion about China revealed that the respondents in most of the 22 polled countries viewed China's global presence and its economic power positively (Program on International Policy Attitude 2005). At the same time, China's growing military might was perceived negatively by $59 \%$ of the respondents. It is interesting to note that the younger respondents or those between 18 and 29 years old had more positive perceptions about the country compared to the older people. 
A more recent poll conducted in 2011 registered a shift in public opinion (BBC 2011). The negative perceptions about China became stronger. However, the attitudes varied across the continents. The respondents in African and Latin American countries held the most positive perceptions about China. While there is no poll data available about the Malaysians' sentiments, the respondents in the polled Southeast Asian countries, such as the Philippines and Indonesia, had strongly positive views about China.

The Chinese government realizes the need for an improved international image of the country in order to match it with China's increasing economic and political influence in the world. In recent years China has organized and hosted several high profile international events, such as the Olympic Games in 2008 and the World Expo in 2010. Simultaneously, the government has intensified its efforts to promote Chinese culture and language abroad through setting up and financing the Confucius Institutes. Currently, there are more than 300 Confucius Institutes all over the world, including one in Malaysia (Xinhua News Agency 2010). Several researchers have described these efforts as China's aspiration to enhance and exercise its 'soft power' (Ding and Saunders 2006, Hartig 2012, Huang and Ding 2006, Li and Worm 2011, Zhao and Huang 2010). 'Soft power' is a concept developed by Joseph Nye (1990) and it refers to the ability of a country to use its attraction rather than coercion to influence other countries' policies in order to achieve the desired results. Cultural attractiveness is regarded as one of the important elements in the concept of 'soft power'.

The efforts by authorities to enhance a country's soft power can be supported or thwarted by several factors that may influence people's perceptions about that country. Among them scholars recognize the socio-political climate, the economic situation, the mass media and popular culture (Bal-Tar 1997, Ding and Saunders 2006, Realo et al. 2009). For example, Bersick (2010) has noted that the German mass media perpetuates the negative and outdated stereotypes about China. He attributes this to the feelings of uncertainty over the future implications of the rise of China, especially in the wealthier countries. A study of the American mass media's coverage of China by Stepchenkova, Kirilenko and Morrison (2006) revealed that economic issues occupied the most prominent place. The researchers noted that a significant attention was given to the topics related to China's economic growth, the issues of technology transfer as well as to the cultural and educational exchanges between the two countries. The coverage of these topics in the American mass media was predominantly positive. On the other hand, the negative tone dominated in the articles devoted to the issues of human rights and politics in China. At the same time, the journalists and the political analysts held a neutral position while discussing China's Asian politics, the Chinese government and the country's labour market (Stepchenkova, Kirilenko and Morrison 2006).

As Huang and Ding (2006:24) have noted, assessing the effectiveness of soft power can be a 'tricky enterprise' due to the intangible qualities of culture and other aspects that constitute soft power. Nye (2004) has suggested that it is possible to gauge the effectiveness of certain aspects of soft power through hold- 
ing polls or through researching focus groups. However, opinion polls cannot give a reliable picture of the soft power's effectiveness. For example, positive opinions about China voiced by the respondents in African countries (BBC 2011) could be attributed to the economic benefits that Chinese investments brought to these countries just as much as to reflect China's cultural attractiveness. Perhaps a clearer picture of a country's attractiveness and the potency of its soft power could transpire through exploring stereotypical images that people have about this particular country and by assessing the favourability and salience of these stereotypes.

A search of various databases for studies on cultural stereotypes about China and Chinese people written in the English language revealed that academic literature on the topic is not as abundant as we expected. The findings of the available studies indicate that the mass media in Western countries promote negative stereotypes about China (Bersick 2010, Hartig 2012). Some researchers have argued that stereotyping China-made goods as a threat to the economy and employment is widely spread in the American mass media. As a result, the 'Chinaas-a-menace-to-the-world' stereotype has become one of the most lingering images of the country ( $\mathrm{Ng}$, Ye and Lee 2011). A search of popular mass media and the Internet revealed that people in Western countries hold rather narrow and stereotypical views about China. For example, some still believe that streets in Chinese cities are filled with red lanterns, that people in these streets wear traditional clothes and that everyone pursues Confucian values ( $\mathrm{Li}$ and Worm 2011, Roell 2012). During the search for relevant studies on stereotypical presentations of China and Chinese people it came to our attention that the majority of the articles have been produced in the Western context. As a result, they reflect the views and opinions of people in Western countries (Bersick 2010, Lee-Loy 2003, Stepchenkova, Chen and Morrison 2005, Lee and Fiske 2006). The present study explores perceptions about China held by its Asian neighbours, such as young people in Malaysia. This approach is especially relevant because, as Turner (2009) has observed, the ideas that people have at a young age shape a foundation for their later worldview.

The current article focuses on cultural stereotypes about China held by the learners of the Mandarin language in a big public university in Malaysia. Language educators recognize a fact that students come to the classroom with a multitude of their own ideas and opinions about the country, culture and native speakers of the language they learn. These perceptions are often stereotypical as they are not based on solid knowledge of the target language country. Several studies have examined cultural stereotypes held by language learners (Abrams 2002; Kim 2010, Peng 2010, Schultz and Haerle 1995, Vande Berg 1990, Webber 1990). However, the available research is limited to exploring the stereotype content only; assessments of the favourability and salience of these stereotypical images are lacking. It also came to our attention that despite the growing popularity of Mandarin language programs all over the world there is a lack of studies that examine country stereotypes held by the students who learn Mandarin. 
The present study aims to address these gaps in research literature by raising the following questions:

1. What stereotypical images about China do Malaysian learners of the Mandarin language hold?

2. Are these stereotypes positive or negative?

3. How salient are the stereotypes about China?

In order to answer these questions the present study adopts and blends methodological approaches used in various academic disciplines. Thus, methods developed in social psychology (Esses, Haddock and Zanna 1993, SpencerRodgers 2001) will be used to examine the content and the favourability of the students' stereotypes (Questions 1 and 2). To determine the salience of the stereotypical images (Question 3) the study will employ methods used in ethnolinguistics (Smith 1993, Smith et al. 1995, Sutrop 2001).

\section{Literature review}

\subsection{The nature of stereotypes}

The word 'stereotype' usually refers to people's preconceived ideas about the surrounding world. Stereotypes may include the perceptions about other people, countries, cultures, ethnic groups, and so on. Stereotypes have been described as 'pictures in our heads' (Lippmann 1922/1965:3) and are often viewed as the antithesis to the critical thinking (Webber 1990). Whether negative or positive, true or false stereotypes serve as 'short-cuts' in the thinking process (Schultz and Haerle 1995) and they are an integral part of human cognition. People begin to acquire stereotypes in early childhood. As Lippmann (1922/1965:55) has put it, "In the great blooming buzzing confusion of the outer world we pick out what our culture has already defined for us, and we tend to perceive that which we have picked out in the form stereotyped by our culture." The mass media, movies, gossip and anecdotal evidence all play an important role in stereotype formation and perpetuation (Realo et al. 2009). As the pace of globalization accelerates, not only the local but also the global mass media and foreign cultural products (such as news channels, movies, drama serials and TV shows) are becoming increasingly influential in the process of formation of cultural stereotypes and in shaping people's perceptions about other countries.

In studies on cultural stereotypes in the academic field of social psychology a stereotype is considered to exist only when a certain number of respondents have referred to a particular characteristic, descriptor or its synonyms (Spencer-Rodgers 2001). However, there is no established threshold for indicating when a stereotype comes into existence. In some studies a minimum percentage of the respondents' agreement to indicate a stereotype varies between 6\% and 20\% (Echtner and Ritchie 1993, Marin1984, Niemann et al. 1994, Spencer-Rodgers 2001). While considerable research on cultural stereotypes has been done in the academic field of social psychology a deeper exploration of country-related images has been 
carried out in studies on tourism and marketing. Brijs, Bloemer, and Kasper (2011:1260) have argued that the formation of country stereotypes is based on a combination of several aspects, among them "(1) cultural identity, (2) political climate, (3) language, (4) history, (5) climate, (6) landscape, (7) economic and technological development, (8) religion, and (9) people" (Brijs, Bloemer and Kasper 2011:1260). Furthermore, Echtner and Ritchie (1991) proposed that stereotypical perceptions about a country cluster along several continuums, namely, 'attribute-holistic', 'functional-psychological', and 'common-unique'. Especially useful for the purpose of the present study is the 'common-unique' continuum because it allows estimating the width and depth of the language learners' knowledge about the target language country. In this continuum, the 'common' characteristics of a country include general references to its climate, scenery, geographical location, etc. On the other hand, the 'unique' country images make references to the places, events, cities, atmosphere that exist only in that particular country (e.g. Notre Dame cathedral in Paris, the city of Kyoto in Japan, the carnival in Rio de Janeiro). It can be argued that a greater presence of the 'unique' images in people's descriptions of a country might reflect a better knowledge about it.

\section{Background to the study}

\subsection{Socio-cultural context}

Malaysia is a multiethnic and multicultural country in Southeast Asia. Ethnic Chinese make up $24.6 \%$ of the total Malaysian population of 28.3 million and they form one of the three main ethnic groups (Department of Statistics Malaysia 2010). Large numbers of Chinese migrants came to the British Malaya during the 19th century. While making necessary adjustments to the cultural practices of the host country and local communities the Chinese Malaysians have been able to maintain their own cultural identity.

In a broader definition of Chinese cultural sphere researchers distinguish such important aspects as the knowledge of Mandarin or any other Chinese dialect, the observance of Chinese cultural mores and Confucian values (e.g. filial piety, veneration of ancestors, respect for elders and authority), the shared folk epistemologies and lay beliefs which include religious and burial rituals, numerology, feng shui and so on (Ding and Saunders 2006, Spencer-Rodgers, Williams and Peng 2012). In order to preserve their culture the pioneer Chinese migrant communities in the British Malaya established Chinese-medium schools, published local Chinese language newspapers and formed numerous religious, clan and dialects associations (Carstens 2003, Chiu 2000, Lee 1997).

Nowadays, the cultural heritage of the Malaysian Chinese community adds to an exciting blend of cultures in this multiethnic country. For example, several words and expressions from various Chinese dialects have become a part of everyday vocabulary of all Malaysians regardless of their ethnic roots. Among these words are kongsi (association or partnership), towkay (a wealthy Chinese 
businessman, boss), tapau (take away food) and kiasu (fear of losing out to other people) (Hashim and Leitner 2011). Traditional Chinese culture in the forms of cultural practices (e.g. herbal medicine, acupuncture, cuisine, martial arts) as well as celebrations and festivals (e.g. the lunar Chinese New Year) has become an inalienable part of Malaysia's cultural heritage. Furthermore, Malaysian government-sponsored and commercial TV channels broadcast news and various Chinese language programs, such as drama serials, movies, variety shows both locally produced and imported. Satellite TV channel Astro offers to subscribers several packages in various Chinese dialects. All of this means that Malaysians from various ethnic backgrounds, including the participants in the present study, are well acquainted with Chinese traditional and popular culture even if only on a superficial level.

Recognizing the increasingly important status of China as a trade partner and of Mandarin as a language for international business, the Malaysian government lifted all restrictions on Chinese language education in the late 1990s. In 2009, Malaysia and China signed an agreement to establish the first Confucius Institute in the country (Xinhua News Agency 2009). Nowadays, Mandarin classes are offered in national schools at primary and secondary levels. At tertiary level, Mandarin as a foreign language is taught in all big public universities in Malaysia.

\subsection{Educational context}

This study was conducted in a big public university in East Malaysia. According to the university regulations, the students who have good proficiency in English are required to learn a foreign language (e.g. Arabic, French, Japanese, Mandarin or Spanish) or a local language (e.g. Tamil, Kadazan-Dusun) for three semesters. ${ }^{1}$ Generally, they can choose any language program offered by the university depending on the availability of placements. There are, however, some restrictions for the heritage language learners. For example, the students who attended Chinese-medium schools and wish to continue learning Mandarin at the university cannot take the beginner level course; they must register for the advanced level Mandarin classes.

\section{Method}

\subsection{Participants}

The study was conducted among beginner learners of the Mandarin language in their second semester of the language program. A total of 116 students $(\mathrm{N}=116)$ participated in this study.

1 The students who obtain Bands 4, 5 or 6 of the Malaysian University English Test (MUET) are considered to have good proficiency in English. Those who obtain Bands 1, 2 or 3 of the MUET are required to continue studying English at the university and are not allowed to register for a foreign language program. 
They were all Malaysian citizens of various ethnic backgrounds. The majority of the participants were Malay $(n=41)$ followed by Kadazan-Dusun $(n=30)$, Bajau $(n=8)$, Indian $(n=6)$, Iban $(n=6)$, Sino-Kadazan $(n=5)$, Bidayuh $(n=5)$ and representatives of other ethnic groups (e.g., Murut, Iranun, Suluk, Brunei, Kayan, Melanau, Lundayeh).

The age of the participants ranged from 20 to 25; their average age was 20.7 $($ Standard Deviation $=0.734)$. There were significantly more female $(\mathrm{n}=89)$ than male $(n=26)$ participants; one participant did not indicate the gender. Overall, the gender composition of the sample reflects the gender ratio of undergraduate students enrolled in Malaysian public universities.

The participants majored in various academic disciplines, such as the arts and social sciences $(n=33)$, the sciences $(n=21)$, economics and business $(n=20)$, engineering $(n=13)$, psychology $(n=12)$, education $(n=6)$, food science and nutrition $(n=4)$, forestry $(n=4)$ and medicine $(n=3)$.

\subsection{Research instrument}

Each respondent was given a photocopied form that contained one open-ended question with an instruction as follows "What images or ideas come to your mind when you hear the word 'China'? List as many single words or short phrases as you believe is necessary to describe China". Then, the participants were instructed to put a favourability rating next to each image about China they had supplied. The ratings ranged from -3 (to indicate a 'highly negative' attitude) to +3 (to mark a 'highly positive' attitude).

The students were also asked to provide some demographic information, such as their age, gender, ethnic group and academic major. The participants were informed that the purpose of the study was to know opinions about China held by the students who learn the Mandarin language.

\subsection{Data organization and analysis}

The first step in organizing and analyzing the data was to classify and label the images about China supplied by the students. The answers to the open-ended question were typed ad verbatim together with their favourability ratings and the sequence number of each image in the individual list.

Open coding was adopted to classify the images (Ryan and Bernard 2003). The classification procedure was very detailed and thorough. All images mentioned more than once were grouped together (e.g. Great Wall of China, panda, fireworks, discipline). Each group of the images was given a label based on the words or descriptors it contained (e.g. food, Chinese people); these groups formed categories of the students' images about China. Though some images could be grouped together (e.g. food and dumplings) and form one category, we kept them in separate categories in order to identify as much distinctive images of China as possible. 
The following step was to establish which of the categories represented stereotypes. We used frequency analysis for this purpose. This approach is practiced in studies on social psychology that recognize the existence of a stereotype only when a certain number of respondents have given this particular image, descriptor or its synonyms. There is, however, no established minimum percentage of the total responses to indicate a stereotype and it has varied between $6 \%$ and $20 \%$ (Echtner and Ritchie 1993, Marin 1984, Niemann et al. 1994, Spencer-Rodgers 2001). In the present study, the images provided by more than $5 \%(n=6)$ of the participants were considered as stereotypes.

\subsection{Valence rating and mean valence calculation}

The favourability ratings of the images provided by the students were used to calculate their favourability or mean valence. We employed the following formula suggested by Spencer-Rodgers (2001):

$$
M V_{j}=\frac{\sum_{j=1}^{F_{j}} V_{j i}}{F_{j}}
$$

where $M V_{j}$ is mean valence of the stereotypical image $j ; V_{j i}$ is the valence rating given by the student $i$ to each image $j$ within the category; $F_{j}$ is the number of times the image $j$ was mentioned. For example, the students mentioned the 'Great Wall of China' image 67 times $\left(F_{j}=67\right)$. Each student assigned his or her own favourability rating to this image on the scale ranging from -3 to +3 . Employing formula (1), the mean valence $(M V)$ index for 'Great Wall of China' was calculated at 2.73. To ensure a high accuracy the calculations were done using computer software.

Next, in order to examine the overall favourability of the stereotypical images we calculated the composite mean valence $(C M V)$ of the stereotypes about China. The $C M V$ is the overall mean of the $M V_{j}$ for each stereotypical image. The $C M V$ can be obtained from the following calculation (Spencer-Rodgers 2001):

$$
C M V=\frac{\sum_{j=1}^{M} V_{j i}}{M}
$$

where $M$ is the total number of images mentioned by all the students or the sum of each image's frequencies.

\subsection{Salience indices calculation}

In order to analyze the stereotypes' prominence we used three types of salience indices developed by Smith (1993), Smith et al. (1995) and Sutrop (2001). Smith's (1993) free-list salience $(F L S)$ index is able to capture the relative importance of 
an image by considering its position in the list of images or 'free-list'. ${ }^{2}$ Smith et al. (1995) then modified the salience index calculation (see Sutrop 2001 for an overview). A significant contribution to the salience indexing literature has been made by Sutrop (2001) who introduced the cognitive salience (CS) index.

\subsubsection{Free-list salience index}

The free-list salience (FLS) index was developed and verbally explained by Smith (1993). It was then converted by Sutrop (2001) into the following mathematical formula:

$$
F L S_{j}=\frac{\sum_{i=1}^{N} \frac{L_{i}-R_{j i}}{L_{i}}}{N}
$$

where $F L S_{j}$ is the free-list salience index of the stereotypical image $j ; L_{i}$ is the number of images mentioned by the student $i$, and $R_{j i}$ is the rank of the image $j$ in that list of images. The rank of the first image mentioned in the list $L_{i}$ is codified as 0 , the second image is codified as 1 and so on. If a student $i$ did not mention the image $j$ in the list $L_{i}$, the rank of the image $R_{j i}$ would be set as $L_{i}$.

To give an example of this calculation method, let's assume that there are only three students $(N=3)$ in a study. The image 'fireworks' was mentioned by two of them. The first student gave the answer 'fireworks' as the first among 2 images ( $L_{1}=2, R_{j 1}=0$ ); the second student gave the answer 'fireworks' as the fourth among 4 images $\left(L_{2}=4, R_{j 2}=3\right)$ while the third student did not mention this image at all among the three images provided $\left(L_{3}=3, R_{j 3}=3\right)$. Employing formula (3), the free-list salience $(F L S)$ index for the 'fireworks' image is calculated at:

$$
\sum \frac{L_{i}-R_{j i}}{L_{i}} / N=\left(\frac{2-0}{2}+\frac{4-3}{4}+\frac{3-3}{3}\right) / 3=\frac{1.25}{3}=0.41
$$

\subsubsection{Modified free-list salience index}

Smith and his colleagues (1995) introduced the modified free-list salience (MFLS) index. The mathematical formula suggested by Sutrop (2001) to calculate the $M F L S$ index is as follows:

$$
M F L S_{j}=\frac{\sum_{j=1}^{F_{j}} \frac{\left(L_{i}-R_{j i}\right)}{\left(L_{i}-1\right)}}{N}
$$

2 Lists of images about China provided by the participants in this study can be considered as 'freelists'. 
In the MFLS index, the rank of the first image $R_{j i}$ in the list of images $L_{i}$ is codified as 1 , the second image is codified as 2 and so on. Similar to the FLS index, if a student $i$ did not mention the image $j$ in the list $L_{i}$, the rank of the image $R_{j i}$ would be set as $L_{i}$. Employing formula (4) the salience of the 'firework' image in the previous example would be:

$$
\begin{gathered}
\sum \frac{L_{i}-R_{j i}}{L_{i}-1} / N=\left(\frac{2-1}{2-1}+\frac{4-4}{4-1}+\frac{3-3}{3-1}\right) / 3=\frac{1.00}{3}=0.33 \\
\text { 4.5.3. Cognitive salience index }
\end{gathered}
$$

Sutrop (2001) has proposed the following user-friendly formula to calculate the cognitive salience index $(C S)$ :

$$
C S_{j}=\frac{F_{j}}{N\left(m P_{j}\right)}
$$

where $m P_{j}$ is the mean position of the image $j$. The mean position can be calculated as:

$$
m P_{j}=\frac{\sum_{i=1}^{N} R_{j i}}{F_{j}}
$$

In this method, the rank of the first image mentioned in the list of images $L_{i}$ is codified as 1 ; if the image occupied the second position in the list it is codified as 2 and so on, which is similar to the $M F L S$ index. The difference is that if a student $i$ did not mention the image $j$ in his or her list $L_{i}$, the rank of the image $R_{j i}$ is set as 0. Employing formula (5) for the 'fireworks' image example, the cognitive salience $(C S)$ index image is calculated as:

$$
F_{j} / N(m P)=2 / 3\left(\frac{1+4+0}{2}\right)=\frac{2}{7.5}=0.26
$$

\section{Findings}

\subsection{Research question 1: stereotypical images about China}

The students provided a total of 956 responses to the open-ended question. The shortest list contained 2 and the longest one had 21 images. In the first step of the analysis all the images, descriptors or their synonyms were classified into groups. This step yielded 119 groups or categories of images; each contained at least 2 responses. There were also 7 idiosyncratic responses that could not be categorized. 
We adopted $5 \%(\mathrm{n}=6)$ benchmark as the criterion for distinguishing stereotypical images about China. According to this standard, 51 out of the initial 119 categories formed stereotypes; they contained a total of 660 responses.

\subsection{Research question 2: stereotypes' favourability}

The favourability of each category of stereotypical images was calculated using the ratings assigned by the students to each image. Based on thus obtained mean valence values, the 51 categories of stereotypes were divided into three classes, namely: (1) positive stereotypes (mean valence ranging from +3 to +1 ), (2) ambivalent stereotypes (mean valence between +1 and -1 ) and (3) negative stereotypes (mean valence between -1 and -3 ) (see Table 1 in the Appendix).

As the results show, the overwhelming majority of the students' stereotypes about China $(n=41)$ were positive; there were six $(n=6)$ ambivalent and four $(\mathrm{n}=4)$ negative stereotypes. The composite mean valence of the stereotypes was 1.61 ( $\mathrm{SD}=1.70)$; this indicates that, overall, the students' had positive images about China.

\subsection{Research question 3: stereotypes' salience}

The findings from the FLS (Smith 1993) and MFLS (Smith et al. 1995) indices are shown in Table 2. Table 3 reports the finding from the CS index (Sutrop 2001) (see the Appendix). Despite minor discrepancies, overall, the salience ranks of the stereotypical images are consistent across the three indices.

More importantly, as Table 2 and Table 3 show, the ranks of the stereotypical images about China based on the salience indices are in line with the ranks based on the frequency. This means that the most ubiquitous stereotypes about China (i.e. the images mentioned with high frequencies) were at same time the most salient. However, there were several exceptions to this tendency. For example, the image 'Olympic games' had considerably higher salience rank $(C S=28)$ compared to the frequency rank (42) (see Table 3). This means that although some images were mentioned less frequently, they came to the mind of the respondents who provided them more readily and they occupied higher positions in their lists. Conversely, some images had lower salience indices but higher frequencies. One of such images was 'Cheongsam' $(C S=35$; Frequency rank $=19)$ (see Table 3). This indicates that some images came to the minds of the respondents often but they were mentioned as an afterthought and occupied lower positions in their list.

\section{Discussion}

The images about China provided by the students were multiple and diverse. They included references to culture, politics, language, history, climate, landscape, economics, religion and the Chinese people. This finding aligned with the country- 
related aspects identified by Brijs, Bloemer and Kasper (2011) as the most relevant in the formation of country images. Furthermore, to concur with Echtner and Ritchie's (1991) model the participants supplied both common and unique country images. The former included references to China's climate (e.g. cold weather), scenery (e.g. mountains, beautiful scenery), economy (e.g. economy, Made-inChina) and people (e.g. Chinese people, beautiful women). The latter contained references to the distinctive elements of Chinese culture (e.g. Kung Fu), cultural symbols (e.g. dragon), historical sites (e.g. Shaolin Temple, Great Wall of China) and famous landmarks (e.g. Bird Nest Stadium).

Notwithstanding the diversity of the images about China, the data analysis revealed that the majority of them were related to culture, cultural symbols and icons including those from the domain of popular culture. To reflect China's rich cultural heritage the stereotypical images referring to traditional culture and cultural symbols were among the most favourable and prominent. Thus, the images 'Great Wall of China', 'Chinese food', 'culture' and 'Kung Fu' occupied the top ranks according to the frequency, favourability and salience (see Tables 1, 2 and 3 in the Appendix). The respondents also listed such important cultural symbols, as 'dragon', 'red colour', 'panda', 'chopsticks' and 'Cheongsam'. They named Chinese traditional festivals and celebrations ('Chinese New Year', 'Lion Dance') and made references to China's Buddhist heritage ('Buddhism', 'temples', 'Shaolin'). All the images in the domain of Chinese traditional culture had positive mean valences ranging from 2.73 points for the 'Great Wall of China' to 1.17 points for the 'red colour' image. These findings are not surprising owning to a fact that Chinese culture is an integral part of Malaysia's cultural heritage. What came to our attention is that the references to Chinese culture made by the respondents were on a rather surface level. They reflected what is most visible and accessible as well as most widely practiced in the respondents' surroundings.

Besides the traditional culture the images in the domain of popular culture were among the most favourable stereotypes. For example, 'Jackie Chan', who is an internationally famous actor, enjoyed the highest favourability ratings (mean valence $=2.88 ; \mathrm{SD}=0.34)$. It was also among the most frequent and salient images (Frequency rank $=6 ; C S=5$ ) (see Table 3). Other images related to Chinese pop-culture that had positive mean valences exceeding 2 points included 'Jet Li', 'movies', 'actors/actresses', 'badminton', and 'Olympic games'. These findings attest to the immense influence that popular culture has in the formation of country-related stereotypes. At the same time these results highlight limitations that 'made-in-China' cultural products have in shaping young people's perceptions about the country: none of the respondents had mentioned an actor or a movie director from mainland China. This fact lends some support to Huang and Ding's (2006) proposition that despite China's great cultural resources the influence of its contemporary popular culture is indiscernible.

It is perhaps for this reason that some important cultural figures were not mentioned by the students. Among the 956 images about China the standardbearer of Chinese culture and its soft power, Confucius, was mentioned only once. 
There were no references to other cultural icons, such as Mencius or Lao Tse. Only two allusions were made to Chinese literature. One student mentioned the I-Ching, which is one of Chinese classical texts, and one student wrote 'legends'. These omissions indicate that the respondents were more familiar with the most visible aspects of traditional Chinese culture, which agrees with a proposition that stereotypes of the target language country and culture held by language learners tend to be limited to trivial and mundane (Schultz and Haerle 1995). Furthermore, the respondents' lack of awareness of the essence of traditional Chinese culture with its Confucian philosophy and ethics gives empirical support to an observation that traditional Chinese culture and its inherent moral attraction are often overlooked (Huang and Ding 2006).

Other important stereotypes discovered in the course of the data analysis referred to Chinese history, historical heritage and famous historical sites. Among these images were 'emperors', 'Forbidden City', 'history', 'historical places' and 'imperial palaces'. All these stereotypes were favourable with the mean valences ranging from 2.5 points to 1 point. Moreover, 'Forbidden City' (Frequency rank $=19 ; S C=11$ ) and 'emperors' (Frequency rank $=11 ; C S=12$ ) were among the most often-mentioned and salient images about China (See Table 3).

However, compared to the stereotypes about Chinese culture, which contained a number of references to unique cultural phenomena and products, the images referring to Chinese history were somewhat vague. Thus, among the references to 'historical places' only one unique image was given, namely, the 'Forbidden City'. Furthermore, the respondents did not mention even one 'emperor' by the name; neither did they specify any of China's imperial dynasties. There was one historical figure mentioned by the students, namely, Wong Fei-hung who is a folk hero and incidentally a protagonist in a famous Hong Kong television drama serial. These findings lend support to a proposition by Ding and Saunders (2006) that in the increasingly blurred line between information and entertainment the premium is on promoting spectacular sites and events rather than on a deeper exploration of the multifaceted historical heritage of the world's oldest existing civilization.

Several stereotypical images referred to China status as an economic powerhouse. For example, the image 'economy' (Frequency rank $=8$ ) was not only among the most frequent but also among the most favourable (mean valence $=$ 2.17; $\mathrm{SD}=1.20)$ and the most salient $(C S=7)$ images of China (see Tables 1 and $3)$. The country's status as the 'world's factory' was reflected in the images 'Made in China', 'cheap goods' and 'fake goods'. Interestingly, while the images 'fake goods' $(C S=10)$ and 'cheap goods' $(C S=16)$ both had high salience only the latter enjoyed high favourability ratings (mean valence $=2.13 ; \mathrm{SD}=1.41$ ). The respondent disapproved of 'fake goods' (mean valence $=-1.47 ; \mathrm{SD}=1.74$ ) and had ambivalent attitudes toward the 'Made in China' label (mean valence $=0.25$; $\mathrm{SD}=2.01$ ). Furthermore, the recognition of China's economic status was supported by the acknowledgement of the country's influence in the global political arena. The image 'world power' was mentioned often (Frequency rank $=19$ ); it 
had the second highest favourability (mean valence $=2.8 ; \mathrm{SD}=1.75$ ) and high salience $(\mathrm{CS}=14)$.

The respondents were aware of China's status as the most populous country in the world. The image 'large population' was the second most frequent and salient of the images (Frequency rank $=2, C S=2$ ) preceded only by 'Great Wall of China'. However, the participants' attitudes toward China's demography were ambivalent as reflected in the negative mean valence $(-0.60 ; \mathrm{SD}=1.81)$ of this image. It is interesting to note that while the students viewed China's large population in a negative light they expressed even stronger negative feelings toward China's 'one-child policy'. It was one of the most negative stereotypes (mean valence $=-1.67 ; \mathrm{SD}=1.03$ ) though the image had low frequency and low salience (Frequency rank $=42 ; C S=50$ ). Despite the negative perception of China's demographic status none of the stereotypes referring to the people (i.e. 'Chinese people', 'small eyes' and 'beautiful women') had a negative mean valence. The most positive among these images was 'beautiful women' (mean valence $=2.67 ; \mathrm{SD}=0.52$ ) though, admittedly, this stereotype was among the less frequent and less salient images (Frequency rank $=42 ; C S=42$ ).

Only four stereotypes out of fifty-one were negative. In addition to the 'fake goods' and 'one-child policy' images discussed above the negative stereotypes with mean valence below -1 point included 'natural disasters' (mean valence $=$ $-2.83 ; \mathrm{SD}=0.41$ ) and 'communist' (mean valence $=-1.56 ; \mathrm{SD}=1.27$ ). This result is not unexpected: the participants chose to study the Mandarin language by their own volition, which indicates that they had interest toward and liked the country. These results also align with a trend reported by an international poll (PIPA 2005) that young people tended to hold more positive views about China compared to the older respondents.

\section{Conclusion}

The present study addressed two underexplored areas in research literature. Firstly, it examined stereotypes about China held by learners of the Mandarin language; secondly, it assessed the favourability and salience of these stereotypical images. This study was conducted in a multicultural and multiethnic country, Malaysia, where Chinese cultural heritage is an unalienable part of the national culture.

For the respondents in this study mainland China represented a kaleidoscope of images; some of these images formed stereotypes. Mostly the students' stereotypical representations of China were positive, which supports Nye's (2002) proposition that soft power is more likely to be attractive in the context where there are some cultural similarities rather than great cultural disparities. As the findings revealed, the most favourable and salient images provided by the participants referred to Chinese culture and cultural symbols, both traditional and contemporary. 
In view that the participants in this study were university students and the learners of the Mandarin language some pedagogical implications can be drawn from the findings. Scholars agree that among important objectives of any foreign language program are enhancing the learners' cultural awareness, deepening their knowledge of the target language country and promoting a more sophisticated world view (Abrams 2002; Schultz and Haerle 1995, Vande Berg 1990, Webber 1990). Mandarin language educators may or may not support China's aspirations to harness the country's soft power through promoting Chinese culture and language. However, they may want to consider the ways in which stereotypical images held by the language learners could be used as a starting point to deeper explorations of China's cultural and historical heritage as well as its contemporary culture and society.

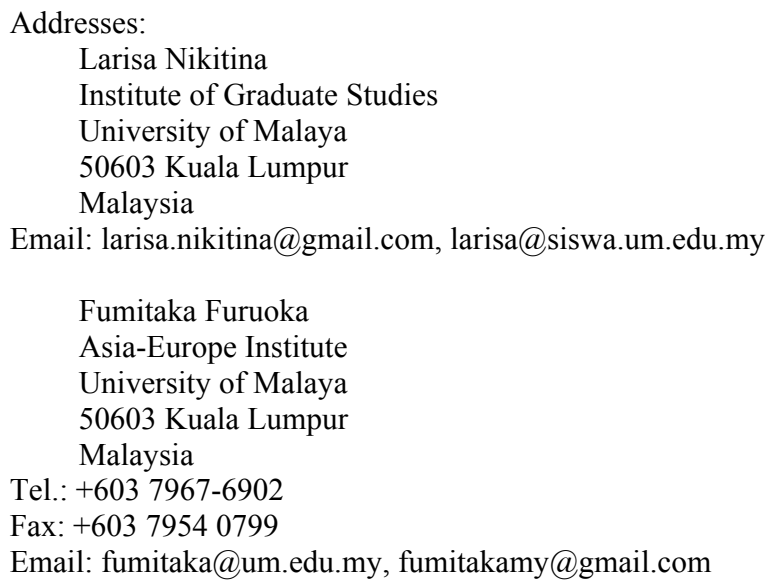

\section{References}

Abrams, Z. I. (2002) "Surfing to cross-cultural awareness: using Internet-mediated projects toexplore cultural stereotypes". Foreign Language Annals 35, 2, 141-160.

Bal-Tar, D. (1997) "Formation and change of ethnic and national stereotypes: an integrative model". International Journal of Intercultural Relations 21, 4, 491-523.

BBC (2011) "Global poll reveals rising concern about China's increasing power". Available online at <http://www.bbc.co.uk/pressoffice/pressreleases/stories/2011/03_march/28/china.shtml $>$. Accessed on 10.05.2012.

Bersick, S. (2010) "Perceptions of Asia in Europe". Asia Europe Journal 8, 245-255.

Brijs, K., J. Bloemer, and H. Kasper (2011) "Country-image discourse model: unravelling meaning, structure, and function of country images”. Journal of Business Research 64,1259-1269.

Carstens, S. A. (2003) "Constructing transnational identities? Mass media and the Malaysian Chinese audience". Ethnic and Racial Studies 26, 2, 321-344.

Castellotti, V. and D. Moore (2002) Social representations of languages and teaching: Guide for the development of language education policies in Europe from linguistic diversity to plurilingual education. Strasbourg: Council of Europe. 
Chiu, Y.-F. (2000) "Educational opportunities for Chinese in Malaysia". Educational Research 33, $585-591$.

Department of Statistics, Malaysia (2010) Population and housing census, Malaysia 2010. Available online at <http://www.statistics.gov.my/portal/download_Population/files/census2010/ Taburan_Penduduk_dan_Ciri-ciri_Asas_Demografi.pdf $>$. Accessed on 19.06.2012.

Ding, S. and R.A. Saunders (2006) "Talking up China: an analysis of China's rising cultural power and global promotion of the Chinese language". East Asia 23, 2, 3-33.

Echtner, C. M. and J. R. B. Ritchie (1993) "The measurement of destination image: an empirical Assessment". Journal of Travel Research 31, 4, 3-13.

Esses, V., Haddock, G. and M. P. Zanna (1993) "Values, stereotypes, and emotions as determinants of intergroup attitudes". In Affect, cognition, and stereotyping: interactive processes in group perception, 137-166. D. M. Mackie and D. L. Hamilton, eds. San Diego, CA: Academic Press.

Gardner, R.C. and W.E. Lambert (1972) Attitudes and motivation in second language learning. Rowley, MA: Newbury House.

Hartig, F. (2012) "Confucius Institutes and the rise of China". Journal of Chinese Political Science $17,53-76$.

Hashim, A. and G. Leitner (2011) "Contact expressions in contemporary Malaysian English". World Englishes 30, 4, 551-568.

Huang, Y., and S. Ding (2006) "Dragon's underbelly: an analysis of China's soft power". East Asia $23,4,22-44$.

Kim, T.-Y. (2010) "Socio-political influences on EFL motivation and attitudes: comparative surveys of Korean high school students". Asia Pacific Education Review 11, 211-222.

Kormos, J. and K. Csizér (2007) "An interview study of inter-cultural contact and its role in language learning in a foreign language environment". System 35, 241-258.

Lee, K. H. (1997) "Malaysian Chinese: seeking identity in Wawasan 2020". In Ethnic Chinese as Southeast Asians, 72-107. L. Suryadinata, ed. Singapore: Institute of Southeast Asian Studies.

Lee, T. L. and S. T. Fiske (2006) "Not an outgroup, not yet an ingroup: immigrants in the stereotype content model". International Journal of Intercultural Relations 30, 751-768.

Lee-Loy, A. M. (2003) “'The Chinese are preferred to all others': nineteenth-century representations of the Chinese in Trinidad and British Guiana". Asian Studies Review 27, 2, $205-225$.

$\mathrm{Li}, \mathrm{X}$. and V. Worm (2011) "Building China's soft power for a peaceful rise". Journal of Chinese Political Science 16, 69-89.

Lippmann, W. (1922/1965) Public opinion. New York: The Free Press.

Marin, G. (1984) "Stereotyping Hispanics: the differential effect of research method, label, and degree of contact". International Journal of Intercultural Relations 8, 17-27.

$\mathrm{Ng}$, S. H., J. Ye., and C.-C. Lee (2011) "Media discourse on globalization in China: a socialpsychological analysis". Journal of Language and Social Psychology 30, 20, 139-157.

Niemann, Y., L. Jennings, R. Rozelle, J. Baxter, and E. Sullivan (1994) "Use of free responses and cluster analysis to determine stereotypes of eight groups". Personality and Social Psychology Bulletin 20, 379-390.

Nye, J. S. (1990) Bound to lead: the changing nature of American power. New York: Basic Books.

Nye, J.S. (2002) The paradox of American power: why the world's only superpower can't do it alone. New York: Oxford University Press.

Nye, J. S. (2004) Soft power:t means to success in world politics. New York: Public Affairs.

Peng, S.-Y. (2010) "Impact of stereotypes on intercultural communication: a Chinese Perspective". Asia Pacific Education Review 11, 243-252.

Program on International Policy Attitude (PIPA) (2005) "22 nation poll shows China viewed positively by most countries". Available online at $<$ http://drum.lib.umd.edu/bitstream/1903/ 10666/2/China_Mar05_art.pdf>. Accessed on 09.05.2012.

Realo, A., J., Allik, J. E. Lönnqvist, M. Verkasalo, A. Kwiatkowska, L. Kööts et al. (2009) "Mechanisms of the national character stereotype: how people in six neighbouring countries 
of Russia describe themselves and the typical Russian”. European Journal of Personality 23(3), 229-249.

Roell, S. (2012) "China stereotypes debunked". Salon. Available online at $<$ http://www.salon.com/ 2012/03/21/china_stereotypes_debunked/>. Accessed on 21.03.2012.

Ryan, G. W. and H. R. Bernard (2003) "Techniques to identify themes". Field Methods 15, 1, 85109.

Schultz, R. A. and B. M. Haerle (1995) "Beer, fast cars, and...: Stereotypes held by U.S. collegelevel students of German". Die Unterrichtspraxis / Teaching German 28, 1, 29-39.

Smith, J. J. (1993). "Using ANTHROPAC 3.5. and a spreadsheet to compute a free-list salience index". Cultural Anthropology Methods 5, 3, 1-3.

Smith, J. J., L. Furbee, K. Maynard, S. Quick and L. Ross (1995). "Salience counts: a domain analysis of English color terms". Journal of Linguistic Anthropology 5, 2, 203-216.

Spencer-Rodgers, J. (2001) "Consensual and individual stereotypic beliefs about international students among American host nationals". International Journal of Intercultural Relations 2, $6,639-657$.

Spencer-Rodgers, J., M. J. Williams, and K. Peng (2012) "Culturally based lay beliefs as a tool for understanding inter-group and intercultural relations". International Journal of Intercultural Relations 36, 2, 169-178.

Stepchenkova, S., Y. Chen, and A. M. Morrison (2005) "China and Russia: a comparative analysis of organic destination images". The 11th APTA Conference Proceedings, vol. 1. New Tourism for Asia-Pacific, 273-283. Goyang, Korea.

Stepchenkova, S., A.P. Kirilenko and A.M. Morrison (2006) "Facilitating statistical analysis of digital textual data: a two-step approach". The 11th annual hospitality and tourism graduate student education and research conference proceedings: Vol. XI. Advances in hospitality and tourism research. Seattle, WA.

Sutrop, U. (2001). "List task and a cognitive salience index". Field Methods 13, 3, 263-276.

Turner, B. (2009) "The perceptions of the European Union among tertiary education students in Singapore”. Asia Europe Journal 7, 225-240.

Vande Berg, C.K. (1990) "Americans viewed by the Spanish: using stereotypes to teach culture." Hispania 73, 2, 518-521.

Webber, M. J. (1990) "Intercultural stereotypes and the teaching of German". Die Unterrichtspraxis / Teaching German 23, 2, 132-141.

Xinhua News Agency (2009) "Malaysia to set up its first Confucius Institute". Available online at $<$ http://english.peopledaily.com.cn/90001/90782/90873/6696582.html>. Accessed on 14.06.2012.

Xinhua News Agency (2010) "316 Confucius Institutes established worldwide". Available online at $<$ http://news.xinhuanet.com/english2010/culture/2010-07/13/c_13398209.htm>. Accessed on 14.07.2012.

Zhao, H. and J. Huang (2010) "China's policy of Chinese as a foreign language and the use of overseas Confucius Institutes”. Educational Research for Policy and Practice 9, 2, 127-142. 
APPENDIX

Table 1. Stereotypical images about China and their favourability

\begin{tabular}{|c|c|c|c|c|c|c|c|}
\hline No & Image & Frequency & $\begin{array}{c}\text { Mean } \\
\text { valence }\end{array}$ & $\begin{array}{c}\text { First } \\
\text { quartile }\end{array}$ & Median & $\begin{array}{c}\text { Third } \\
\text { quartile }\end{array}$ & $\begin{array}{l}\text { Standard } \\
\text { deviation }\end{array}$ \\
\hline & \multicolumn{7}{|l|}{ Positive stereotypes } \\
\hline 1. & Great Wall of China & 67 & 2.73 & 3 & 3 & 3 & 0.62 \\
\hline 2. & Chinese food & 40 & 2.25 & 2 & 3 & 3 & 1.03 \\
\hline 3. & Culture & 30 & 2.13 & 2 & 2 & 3 & 0.86 \\
\hline 4. & Kung Fu & 27 & 2.52 & 2 & 3 & 3 & 0.89 \\
\hline 5. & Jackie Chan & 25 & 2.88 & 3 & 3 & 3 & 0.34 \\
\hline 6. & Lin Dan & 19 & 1.18 & 0 & 1 & 3 & 1.70 \\
\hline 7. & Economy & 18 & 2.17 & 1 & 3 & 3 & 1.20 \\
\hline 8. & Cheap goods & 15 & 2.13 & 1.5 & 3 & 3 & 1.41 \\
\hline 9. & Movies & 13 & 2.42 & 2 & 3 & 3 & 0.79 \\
\hline 10. & Beijing & 13 & 2.08 & 1 & 2 & 3 & 1.04 \\
\hline 11. & Dumplings & 13 & 2.00 & 1 & 2 & 3 & 1.08 \\
\hline 12. & Temples & 13 & 1.23 & 0 & 1 & 2 & 1.36 \\
\hline 13. & Dragon & 11 & 2.00 & 1.5 & 2 & 3 & 1.18 \\
\hline 14. & World power & 10 & 2.8 & 3 & 3 & 3 & 1.75 \\
\hline 15. & Cheongsam & 10 & 2.00 & 2 & 2 & 3 & 0.94 \\
\hline 16. & Forbidden City & 10 & 2.00 & 2 & 2 & 3 & 1.15 \\
\hline 17. & Cold weather & 10 & 1.89 & 2 & 3 & 3 & 1.76 \\
\hline 18. & Language & 10 & 1.80 & 1 & 2 & 3 & 1.14 \\
\hline 19. & Martial arts & 9 & 2.22 & 1 & 3 & 3 & 0.97 \\
\hline 20. & Big country & 9 & 1.88 & 1 & 2 & 3 & 1.13 \\
\hline 21. & Buddhism & 9 & 1.11 & 0 & 1 & 2 & 1.05 \\
\hline 22. & Interesting places & 8 & 2.25 & 2 & 2 & 3 & 0.71 \\
\hline 23. & History & 8 & 2.13 & 1 & 2.5 & 3 & 0.99 \\
\hline 24. & Nice buildings & 8 & 1.38 & 0 & 2 & 3 & 1.85 \\
\hline 25. & Actors/actresses & 7 & 2.67 & 3 & 3 & 3 & 0.82 \\
\hline 26. & Chinese New Year & 7 & 2.57 & 2 & 3 & 3 & 0.53 \\
\hline 27. & Mountains & 7 & 2.43 & 2.5 & 3 & 3 & 1.13 \\
\hline 28. & Jet Li & 7 & 2.43 & 2.5 & 3 & 3 & 1.13 \\
\hline 29. & Four seasons & 7 & 2.29 & 1.5 & 3 & 3 & 0.95 \\
\hline 30. & Badminton & 7 & 2.14 & 2 & 2 & 3 & 1.07 \\
\hline 31. & Shaolin Temple & 7 & 2.00 & 1 & 3 & 3 & 1.41 \\
\hline 32. & Lion Dance & 7 & 1.86 & 1.5 & 2 & 2.5 & 1.07 \\
\hline 33. & Chopsticks & 7 & 1.43 & 0.5 & 1 & 2.5 & 1.27 \\
\hline 34. & Panda & 6 & 2.67 & 3 & 3 & 3 & 0.87 \\
\hline 35. & Beautiful women & 6 & 2.67 & 2 & 3 & 3 & 0.52 \\
\hline 36. & Beautiful scenery & 6 & 2.67 & 3 & 3 & 3 & 0.82 \\
\hline 37. & Imperial palaces & 6 & 2.50 & 2 & 2.5 & 3 & 0.55 \\
\hline 38. & Bird Nest stadium & 6 & 2.50 & 2 & 3 & 3 & 0.84 \\
\hline 39. & Olympic Games & 6 & 2.17 & 1 & 2.5 & 3 & 0.98 \\
\hline 40. & Historical places & 6 & 1.83 & 1 & 2.5 & 3 & 1.6 \\
\hline \multirow[t]{2}{*}{41.} & Red colour & 6 & 1.17 & 0 & 1 & 2 & 1.17 \\
\hline & \multicolumn{7}{|l|}{$\begin{array}{l}\text { Ambivalent } \\
\text { stereotypes }\end{array}$} \\
\hline 1. & Large population & 54 & -0.60 & -2 & -1 & 1 & 1.81 \\
\hline 2. & Emperors & 14 & 0.85 & 0 & 0 & 2 & 1.07 \\
\hline 3. & 'Made in China' & 12 & 0.25 & -1 & 0 & 1.5 & 2.01 \\
\hline
\end{tabular}




\begin{tabular}{l|l|c|c|r|r|r|c}
\hline No & \multicolumn{1}{|c|}{ Image } & Frequency & $\begin{array}{c}\text { Mean } \\
\text { valence }\end{array}$ & $\begin{array}{c}\text { First } \\
\text { quartile }\end{array}$ & Median & $\begin{array}{c}\text { Third } \\
\text { quartile }\end{array}$ & $\begin{array}{c}\text { Standard } \\
\text { deviation }\end{array}$ \\
\hline 4. & Small eyes & 9 & 0.56 & 0 & 0 & 1 & 1.59 \\
5. & Chinese people & 8 & 0.75 & 0 & 0.5 & 1.5 & 1.28 \\
6. & Politics & 7 & -0.29 & -0.5 & 0 & 0 & 1.50 \\
& Negative stereotypes & & & & & & \\
1. & Fake goods & 17 & -1.47 & -3 & -2 & 0 & 1.74 \\
2. & Communist & 11 & -1.27 & -2.5 & -1 & 0 & 1.27 \\
3. & $\begin{array}{l}\text { One-child policy } \\
\text { 4. }\end{array}$ & 6 & -1.67 & -2 & -2 & -1 & 1.03 \\
& Natural disaster & 6 & -2.83 & -3 & -3 & -3 & 0.41 \\
\hline & $\begin{array}{l}\text { Composite mean } \\
\text { valence of stereo- } \\
\text { types }\end{array}$ & $\mathbf{6 6 0}$ & $\mathbf{1 . 6 1}$ & $\mathbf{1}$ & $\mathbf{2}$ & $\mathbf{3}$ & $\mathbf{1 . 7 0}$ \\
\hline
\end{tabular}


Table 2. Findings from Free-list Salience (FLS) index (Smith 1993) and Modified Free-list Salience (MFLS) index (Smith et al. 1995)

\begin{tabular}{|c|c|c|c|c|c|c|c|}
\hline No. & Image & Frequency & Rank & $\begin{array}{l}F L S \\
\text { index }\end{array}$ & Rank & $\begin{array}{c}M F L S \\
\text { index }\end{array}$ & Rank \\
\hline 1. & Great Wall of China & 67 & 1 & 0.432 & 1 & 0.411 & 1 \\
\hline 2. & Large population & 54 & 2 & 0.317 & 2 & 0.293 & 2 \\
\hline 3. & Chinese food & 40 & 3 & 0.180 & 3 & 0.154 & 3 \\
\hline 4. & Culture & 30 & 4 & 0.144 & 4 & 0.123 & 6 \\
\hline 5. & Kung Fu & 27 & 5 & 0.141 & 5 & 0.130 & 4 \\
\hline 6. & Jackie Chan & 25 & 6 & 0.138 & 6 & 0.128 & 5 \\
\hline 7. & Lin Dan & 19 & 7 & 0.100 & 7 & 0.094 & 7 \\
\hline 8. & Economy & 18 & 8 & 0.096 & 8 & 0.087 & 8 \\
\hline 9. & Fake goods & 17 & 9 & 0.071 & 11 & 0.060 & 13 \\
\hline 10. & Cheap goods & 15 & 10 & 0.049 & 19 & 0.039 & 23 \\
\hline 11. & Emperors & 14 & 11 & 0.067 & 12 & 0.060 & 12 \\
\hline 12. & Movies & 13 & 12 & 0.043 & 24 & 0.032 & 31 \\
\hline 13. & Beijing & 13 & 12 & 0.079 & 9 & 0.075 & 9 \\
\hline 14. & Dumplings & 13 & 12 & 0.071 & 10 & 0.068 & 10 \\
\hline 15. & Temples & 13 & 12 & 0.056 & 17 & 0.049 & 17 \\
\hline 16. & 'Made in China' & 12 & 16 & 0.041 & 27 & 0.033 & 29 \\
\hline 17. & Dragon & 11 & 17 & 0.058 & 16 & 0.054 & 16 \\
\hline 18. & Communist & 11 & 17 & 0.062 & 14 & 0.059 & 14 \\
\hline 19. & World power & 10 & 19 & 0.053 & 18 & 0.047 & 18 \\
\hline 20. & Cheongsam & 10 & 19 & 0.035 & 29 & 0.030 & 32 \\
\hline 21. & Forbidden City & 10 & 19 & 0.064 & 13 & 0.061 & 11 \\
\hline 22. & Cold weather & 10 & 19 & 0.046 & 20 & 0.041 & 21 \\
\hline 23. & Language & 10 & 19 & 0.043 & 25 & 0.038 & 25 \\
\hline 24. & Martial arts & 9 & 24 & 0.045 & 22 & 0.042 & 19 \\
\hline 25. & Big country & 9 & 24 & 0.046 & 21 & 0.041 & 22 \\
\hline 26. & Buddhism & 9 & 24 & 0.030 & 37 & 0.023 & 40 \\
\hline 27. & Small eyes & 9 & 24 & 0.059 & 15 & 0.057 & 15 \\
\hline 28. & Interesting places & 8 & 24 & 0.030 & 38 & 0.019 & 43 \\
\hline 29. & History & 8 & 24 & 0.021 & 47 & 0.014 & 50 \\
\hline 30. & Nice buildings & 8 & 24 & 0.043 & 26 & 0.038 & 24 \\
\hline 31. & Chinese people & 8 & 24 & 0.033 & 33 & 0.029 & 33 \\
\hline 32. & Actors/actresses & 7 & 32 & 0.030 & 36 & 0.026 & 36 \\
\hline 33. & Chinese New Year & 7 & 32 & 0.019 & 50 & 0.014 & 49 \\
\hline 34. & Mountains & 7 & 32 & 0.035 & 30 & 0.033 & 30 \\
\hline 35. & Jet Li & 7 & 32 & 0.043 & 23 & 0.042 & 20 \\
\hline 36. & Four seasons & 7 & 32 & 0.027 & 40 & 0.024 & 38 \\
\hline 37. & Badminton & 7 & 32 & 0.031 & 35 & 0.027 & 34 \\
\hline 38. & Shaolin Temple & 7 & 32 & 0.038 & 28 & 0.036 & 26 \\
\hline 39. & Lion Dance & 7 & 32 & 0.026 & 42 & 0.022 & 41 \\
\hline 40. & Chopsticks & 7 & 32 & 0.024 & 43 & 0.021 & 42 \\
\hline 41. & Politics & 7 & 32 & 0.032 & 34 & 0.027 & 35 \\
\hline 42. & Panda & 6 & 42 & 0.027 & 39 & 0.025 & 37 \\
\hline 43. & Beautiful women & 6 & 42 & 0.019 & 51 & 0.013 & 51 \\
\hline 44. & Beautiful scenery & 6 & 42 & 0.023 & 45 & 0.018 & 45 \\
\hline 45. & Imperial palaces & 6 & 42 & 0.021 & 46 & 0.017 & 46 \\
\hline 46. & Bird Nest stadium & 6 & 42 & 0.026 & 41 & 0.023 & 39 \\
\hline 47. & Olympic Games & 6 & 42 & 0.035 & 31 & 0.033 & 27 \\
\hline 48. & Historical places & 6 & 42 & 0.024 & 44 & 0.019 & 44 \\
\hline 49. & Red colour & 6 & 42 & 0.035 & 32 & 0.033 & 28 \\
\hline 50. & One-child policy & 6 & 42 & 0.020 & 48 & 0.016 & 48 \\
\hline 51. & Natural disaster & 6 & 42 & 0.020 & 49 & 0.017 & 47 \\
\hline
\end{tabular}


Table 3. Findings from Cognitive Salience (CS) index (Sutrop 2001)

\begin{tabular}{|c|c|c|c|c|c|c|c|}
\hline No. & Image & Frequency & Rank & $\begin{array}{c}\text { Mean } \\
\text { position }(\mathrm{mP})\end{array}$ & Rank & $C S$ index & Rank \\
\hline 1. & Great Wall of China & 67 & 1 & 3.268 & 1 & 0.1767 & 1 \\
\hline 2. & Large population & 54 & 2 & 3.722 & 3 & 0.1250 & 2 \\
\hline 3. & Chinese food & 40 & 3 & 5.300 & 21 & 0.0650 & 3 \\
\hline 4. & Culture & 30 & 4 & 4.466 & 10 & 0.0579 & 4 \\
\hline 5. & Kung Fu & 27 & 5 & 5.444 & 23 & 0.0427 & 6 \\
\hline 6. & Jackie Chan & 25 & 6 & 4.920 & 17 & 0.0438 & 5 \\
\hline 7. & Lin Dan & 19 & 7 & 5.842 & 29 & 0.0280 & 9 \\
\hline 8. & Economy & 18 & 8 & 4.333 & 7 & 0.0358 & 7 \\
\hline 9. & Fake goods & 17 & 9 & 5.647 & 25 & 0.0259 & 10 \\
\hline 10. & Cheap goods & 15 & 10 & 6.800 & 42 & 0.0190 & 16 \\
\hline 11. & Emperors & 14 & 11 & 5.714 & 26 & 0.0211 & 12 \\
\hline 12. & Movies & 13 & 12 & 6.153 & 34 & 0.0182 & 18 \\
\hline 13. & Beijing & 13 & 12 & 3.923 & 4 & 0.0285 & 8 \\
\hline 14. & Dumplings & 13 & 12 & 5.538 & 24 & 0.0202 & 13 \\
\hline 15. & Temples & 13 & 12 & 6.153 & 35 & 0.0182 & 17 \\
\hline 16. & 'Made in China' & 12 & 16 & 6.750 & 41 & 0.0153 & 23 \\
\hline 17. & Dragon & 11 & 17 & 5.272 & 20 & 0.0179 & 19 \\
\hline 18. & Communist & 11 & 17 & 4.909 & 16 & 0.0193 & 15 \\
\hline 19. & World power & 10 & 19 & 4.400 & 8 & 0.0195 & 14 \\
\hline 20. & Cheongsam & 10 & 19 & 8.000 & 49 & 0.0107 & 35 \\
\hline 21. & Forbidden City & 10 & 19 & 3.400 & 2 & 0.0253 & 11 \\
\hline 22. & Cold weather & 10 & 19 & 5.800 & 27 & 0.0148 & 25 \\
\hline 23. & Language & 10 & 19 & 6.700 & 40 & 0.0128 & 29 \\
\hline 24. & Martial arts & 9 & 24 & 6.000 & 31 & 0.0129 & 27 \\
\hline 25. & Big country & 9 & 24 & 4.666 & 14 & 0.0166 & 22 \\
\hline 26. & Buddhism & 9 & 24 & 6.333 & 36 & 0.0122 & 31 \\
\hline 27. & Small eyes & 9 & 24 & 4.444 & 9 & 0.0174 & 20 \\
\hline 28. & Interesting places & 8 & 24 & 4.625 & 13 & 0.0149 & 24 \\
\hline 29. & History & 8 & 24 & 7.250 & 45 & 0.0095 & 40 \\
\hline 30. & Nice buildings & 8 & 24 & 4.125 & 6 & 0.0167 & 21 \\
\hline 31. & Chinese people & 8 & 24 & 6.000 & 32 & 0.0114 & 32 \\
\hline 32. & Actors/actresses & 7 & 32 & 5.428 & 22 & 0.0111 & 34 \\
\hline 33. & Chinese New Year & 7 & 32 & 7.857 & 48 & 0.0076 & 47 \\
\hline 34. & Mountains & 7 & 32 & 5.857 & 30 & 0.0103 & 37 \\
\hline 35. & Jet Li & 7 & 32 & 4.571 & 12 & 0.0132 & 26 \\
\hline 36. & Four seasons & 7 & 32 & 7.142 & 44 & 0.0084 & 43 \\
\hline 37. & Badminton & 7 & 32 & 6.428 & 38 & 0.0093 & 41 \\
\hline 38. & Shaolin Temple & 7 & 32 & 6.142 & 33 & 0.0098 & 39 \\
\hline 39. & Lion Dance & 7 & 32 & 7.285 & 46 & 0.0082 & 44 \\
\hline 40. & Chopsticks & 7 & 32 & 8.285 & 50 & 0.0072 & 49 \\
\hline 41. & Politics & 7 & 32 & 4.857 & 15 & 0.0124 & 30 \\
\hline 42. & Panda & 6 & 42 & 6.666 & 39 & 0.0077 & 46 \\
\hline 43. & Beautiful women & 6 & 42 & 5.833 & 28 & 0.0088 & 42 \\
\hline 44. & Beautiful scenery & 6 & 42 & 6.333 & 37 & 0.0081 & 45 \\
\hline 45. & Imperial palaces & 6 & 42 & 7.000 & 43 & 0.0073 & 48 \\
\hline 46. & Bird Nest stadium & 6 & 42 & 5.166 & 19 & 0.0100 & 38 \\
\hline 47. & Olympic Games & 6 & 42 & 4.000 & 5 & 0.0129 & 28 \\
\hline 48. & Historical places & 6 & 42 & 4.500 & 11 & 0.0114 & 33 \\
\hline 49. & Red colour & 6 & 42 & 5.000 & 18 & 0.0103 & 36 \\
\hline 50. & One-child policy & 6 & 42 & 7.500 & 47 & 0.0068 & 50 \\
\hline 51. & Natural disaster & 6 & 42 & 8.500 & 51 & 0.0060 & 51 \\
\hline
\end{tabular}

